\title{
Apreciação ética de projectos de investigação em saúde: uma reflexão situada a propósito da ética de investigação em ciências sociais ${ }^{1}$ Hélder Raposo ${ }^{2}$
}

Resumo: Tomando como ponto de partida uma experiência de colaboração numa comissão de ética de saúde, a presente proposta procura constituir-se como um exercício reflexivo sobre o percurso de participação decorrente do vínculo formal a uma estrutura desta natureza. No entanto, mais do que apenas apresentar um testemunho pessoal que ponha em evidência a visão de um sociólogo relativamente à integração e participação num órgão colegial e multidisciplinar orientado para as questões da saúde, ensaio um exercício analítico orientado para a compreensão e discussão das particularidades do papel e da acção desta estrutura em matéria de apreciação e deliberação ética de projectos de investigação.

Palavras-chave: Comissões de ética, multidisciplinariedade, investigação em saúde, ciências sociais.

\section{Ethical appraisal of health research projects: A situated reflection on the ethics of research in}

the social sciences

\begin{abstract}
Taking as its starting point a collaborative experience in health ethics committee, this proposal aims to establish itself as a reflexive exercise about the formal participation in this kind of structure. However, more than just present a personal testimony that highlights the vision of a sociologist regarding his integration and participation in a collegiate and multidisciplinary body that is oriented to health issues, I develop an analytical exercise oriented to understanding and discussing the particularities of the role of this structure in terms of appreciation and ethical deliberation of research projects.
\end{abstract}

Keywords: ethics committees, multidisciplinary, health research, social sciences.

\footnotetext{
1 O presente texto tem na sua base uma comunicação apresentada no "Simpósio de Investigação sociológica em saúde: questões éticas" que foi organizado pela Secção Temática de Sociologia da Saúde da APS, tendo o mesmo ocorrido em 11/12/2015 no Instituto Superior de Ciências da Saúde Egas Moniz.

2 Docente na Escola Superior de Tecnologia da Saúde de Lisboa (ESTeSL-IPL), investigador no Centro de Investigação e Estudos em Sociologia do Instituto Superior de Ciências do Trabalho e da Empresa (CIESISCTE/IUL), Membro da Secção de Ética Assistencial da ARSLVT, Membro da Equipa Coordenadora da Secção "Conhecimento, Ciência e Tecnologia" da Associação Portuguesa de Sociologia. helder.raposo@,estesl.ipl.pt.
} 


\section{Introdução}

A investigação científica em áreas específicas como a saúde, encontra-se hoje, e cada vez mais, integrada num panorama regulatório abrangente, complexo e exigente que tem como um dos seus aspectos basilares a institucionalização da ética, concretamente por via da proliferação das chamadas Comissões de Ética para a Saúde (CES). Trata-se, com efeito, de uma tendência que, pese embora ter sido inicialmente moldada e impulsionada no contexto da regulação da investigação biomédica norte-americana, é hoje transversal a praticamente todas as latitudes geográficas, sendo, como tal, um processo notoriamente global.

Nesta medida, tornou-se consensual, e está, de resto, formalmente consagrado do ponto de vista legal, o pressuposto de que no quadro da análise e da salvaguarda dos princípios éticos e das boas práticas no contexto da investigação em áreas como a saúde, terá de ser consignada às CES a responsabilidade de garantir a revisão independente dos protocolos de investigação que lhes sejam submetidos com vista à elaboração de pareceres sobre a observância dos padrões éticos. O cumprimento deste grande objectivo pressupõe, em termos práticos, o desenvolvimento de um processo de análise e avaliação da fundamentação das propostas, nomeadamente no que concerne à identificação das garantias relativas aos instrumentos e procedimentos que salvaguardam, do ponto de vista ético, os direitos dos sujeitos (utentes, profissionais de saúde ou outros profissionais) a envolver nos processos de investigação.

No caso do exemplo específico subjacente à presente reflexão - baseado na experiência de participação do autor na CES da Administração Regional de Saúde de Lisboa e Vale do Tejo (ARSLVT) - verifica-se que tal assim acontece, uma vez que enquanto órgão colegial e multidisciplinar que desenvolve um trabalho consultivo de apoio (tanto no domínio da ética de investigação, mas também no domínio da ética assistencial) ao Conselho Directivo da ARSLVT, esta CES é responsável pela elaboração de pareceres referentes a pedidos de investigação a ser desenvolvidos na sua área geográfica de actuação, designadamente no contexto dos cuidados de saúde primários. Tal significa que é com base em directrizes éticas relativas à investigação com seres humanos, com incidência nas várias áreas disciplinares e nas diferentes comunidades científicas, que se estabelecem princípios e procedimentos que passam a constituir-se como referenciais incontornáveis para a prossecução da própria investigação. Como consequência directa, a viabilidade desta passa, também, a depender da conformidade dos projectos e protocolos a este quadro de regulação. Tendo isto em 
consideração, cabe perguntar como é que tal se tem traduzido na actividade de investigação das ciências sociais, e concretamente da Sociologia, quando estas elegem, justamente, o campo da saúde como o contexto dos seus objectos de estudo?

\section{Objectivos}

Para procurar dar resposta a esta interrogação geral, o contributo que com esta proposta pretendo desenvolver passa pela realização de uma reflexão que está empírica e operacionalmente ancorada num processo de levantamento e de sistematização das actividades da secção de investigação da CES-ARSLVT (a produção de pareceres deliberativos sobre os projectos apresentados) no período compreendido entre Julho de 2012 e Junho de 2015, ou seja, o período referente ao primeiro triénio de actividade da actual comissão. A abordagem ao tratamento deste tipo de informação tem, assim, em vista o ensaio de um exercício analítico orientado para a compreensão e discussão das particularidades do papel e da acção desta estrutura em matéria de apreciação ética dos projectos de investigação.

Para tal, procedi numa primeira fase ao inventário do volume de projectos submetidos para apreciação, assim como ao mapeamento de alguns aspectos gerais caracterizadores das propostas (origem disciplinar dos investigadores/entidades proponentes, tipo de estudo académico, de intervenção, etc.). Numa segunda fase, e por razões que se prendem acima de tudo com a filiação científica do autor, foi dado um especial enfoque ao conjunto das propostas que disciplinarmente se enquadram no âmbito das ciências sociais, e muito em particular na sociologia e na Antropologia. O enfoque circunscrito desta opção permite proceder à tipificação das observações e/ou objecções predominantes, sinalizar as discussões que as mesmas tendem a suscitar, mas também, e em função disso, aferir em que medida o desenvolvimento da investigação neste campo científico tem integrado, e se tem confrontado, com referenciais e com procedimentos cujo carácter relativamente padronizado pode colocar exigências potencialmente desajustadas a tradições de investigação cuja epistemologia as afasta, pela sua especificidade (como é em particular o caso da investigação qualitativa), da tradição da investigação clínica e biomédica que está mais convencionalmente disseminada até pela própria genealogia da bioética (Cascais, 2002, 2015) - no campo da saúde.

Assim sendo, é pois, com base neste acervo documental mais específico, que aqui procuro identificar e discutir quais as questões que tendem a ser denotativas das especificidades da 
investigação nestes domínios disciplinares, os aspectos que, em função disso, se revelam como potencialmente geradores de formas distintas de pensar os posicionamentos sobre a ética da investigação, bem como os respectivos desafios que daqui emergem para os próprios modelos da deliberação ética.

\section{Metodologia}

Face ao exposto, trata-se, portanto, de desenvolver um exercício de análise baseado num pequeno estudo descritivo alicerçado na técnica da análise documental relativamente ao conjunto dos processos que foram analisados pela CES durante o período cuja delimitação já aqui se apresentou ${ }^{3}$. A consulta e a sistematização da informação foram desenvolvidas com base num acervo composto por um total de 253 processos, tendo sido objecto de uma análise mais aprofundada apenas um conjunto mais restrito de 11 processos e respectivos pareceres, provenientes do já referido subuniverso ${ }^{4}$ de propostas (de um total de 44) que se reportam às áreas disciplinares das ciências sociais. Neste último caso, para além de se estimar a proporção quantitativa destes processos face ao volume total de todas as propostas, procedeuse a uma caracterização relativa ao âmbito dos estudos, a sua orientação metodológica, o tipo de população a estudar e, sobretudo, o tipo de objecções colocadas e seus respectivos fundamentos.

\section{A institucionalização das CES: regulação ética, referenciais normativos e codificação formal da investigação}

A actual institucionalização das CES corresponde a uma das faces visíveis da emergência e desenvolvimento da Bioética, processo esse que ocorre fundamentalmente a partir da

\footnotetext{
$3 \mathrm{O}$ acesso à documentação em causa implicou, não obstante o vínculo do autor a esta CES, a apresentação prévia de uma proposta onde se apresentou e sustentou qual o âmbito e os objectivos deste processo de recolha. A proposta foi depois apreciada (nos mesmos trâmites dos processos que chegam à CES) pela secção de investigação que deliberou positivamente. Por uma questão de conflito de interesses nunca poderia fazer parte desse processo de deliberação, mas neste caso a questão nem se colocou porque poucos meses antes passei a estar integrado na secção da ética assistencial, o que significa que deixei de ter qualquer participação nas reuniões de trabalho relativas à discussão dos projectos apresentados e das respectivas propostas de parecer.

4 Como será descrito em considerações posteriores, este subuniverso de projectos provenientes das ciências sociais, totaliza 44 projectos, contudo o enfoque da análise centra-se naqueles que dizem especificamente respeito à Sociologia (7) e também à Antropologia (4). Neste último caso a opção por esta agregação justifica-se pelo facto de existirem, do ponto de vista metodológico, maiores convergências e afinidades nos projectos com esta origem disciplinar, designadamente por serem estes projectos aqueles que tendem a remeter mais recorrentemente para abordagens de natureza qualitativa.
} 
década de 1970, e designadamente no contexto norte-americano (Cascais, 2002, 2015; Orfali, DeVries, 2010; Marques, 2015). Em concreto, a Bioética é um neologismo construído a partir das palavras gregas bios (vida) e da palavra ethos (relativo à ética, i.e, ao modo de ser, morada, carácter). É, portanto, uma ética aplicada. É, segundo a definição da Unesco, “ (...) um campo de estudo sistemático, plural e interdisciplinar, envolvendo questões morais teóricas e práticas, levantadas pela medicina e ciências da vida, enquanto aplicada aos seres humanos e a relação destes com a biosfera.” (Unesco, 2005).

As razões principais que desencadearam o seu desenvolvimento tendem a ser frequentemente associadas ao surgimento de um conjunto amplo e inusitado de problemas e dilemas éticos directamente decorrentes dos rápidos avanços científicos e tecnológicos ocorridos na medicina e na biologia da segunda metade do século XX. Muita da novidade e da complexidade dos desafios que vão sendo instaurados remete para o facto de passar a ser efectivamente possível intervir na história natural da saúde e da doença, ou se quisermos, na própria vida humana, designadamente nos processos tanto do princípio como do fim da vida.

Mas para além deste panorama de rápidas e amplas inovações que fazem salientar a premência de novas respostas, o factor que se revela como estruturante e decisivo para a emergência da Bioética é o que diz respeito a uma notória crise de auto-regulação das profissões técnicas e científicas (Cascais, 2002, 2015), sobretudo depois de estas passarem a transportar o anátema associado às perversidades da investigação biomédica em múltiplas situações onde os investigadores expuseram de forma irresponsável vários sujeitos a malefícios potencialmente elevados (como foi, entre outros, o caso paradigmático da vacina da varíola), sendo, no entanto, o pináculo dessa imagem negativa a experimentação radical com seres humanos ocorrida no contexto dos campos de concentração nazis. É, aliás, esse negro episódio da investigação médica que acaba por estar na origem, em 1947, da Declaração de Nuremberga, ou seja, o primeiro documento internacional com directrizes rígidas e específicas para a investigação clínica com seres humanos.

Com efeito, a Declaração de Nuremberga inicia um percurso de produção normativa assinalável, destacando-se como alguns dos marcos principais neste domínio a Declaração de Helsínquia em 1964 (ainda hoje usada para regular a investigação médica, tendo sido, entretanto, objecto de revisões periódicas), o Relatório Belmont em 1979, ou a Convenção de Oviedo em 1997. De notar que, ao nível dos princípios e dos fundamentos, aquilo que esta 
produção de referenciais normativos reflecte, consagra e institui corresponde ao que vários autores têm designado como o modelo fundacional da própria bioética; ou seja, o Principialismo. Este modelo corresponde à assunção de uma ética também designada como secular dado que se afirmou num contexto crescentemente marcado por notória uma crise de representatividade social das tradicionais referências de autoridade moral (religiosa ou confessional) para responder aos novos problemas e dilemas.

Ao nível da natureza dos seus fundamentos, importa notar que a hegemonia deste modelo, de matriz norte-americana, confere grande centralidade aos princípios do individualismo e da autonomia e caracteriza-se por ter um carácter formal, procedimental e universalista relativamente aos pressupostos normativos nos processos de deliberação ética. Nesta medida, os princípios éticos basilares que passaram a conhecer uma legitimidade socialmente sancionada são, pois, os que assentam nos valores da autonomia, beneficiência, não maleficiência e justiça, sendo esta a base principal dos critérios que são privilegiadamente mobilizados para a deliberação ética em contextos dilemáticos.

Daqui têm resultado, no entanto, algumas críticas, nomeadamente as que apontam para a tendência para tratar de modo mecânico os problemas éticos - no sentido em que, em última instância, tudo parece acabar por convergir para a questão da autonomia e para a observância estrita dos princípios a esta associados (Fins, Gracia, 2015) -, mas também as que fazem menção, na senda das observações críticas de Reneé Fox, ao cariz etnocêntrico do paradigma da autonomia e da filosofia analítica do pensamento ético, no sentido do universalismo da aplicação dos princípios ser potencialmente desajustado da realidade de contextos socioculturais distintos da matriz ocidental e da anglo-americana em particular (Lopez, 2004; Orfali, DeVries, 2010; Marques, 2015). Também a referência ao desenvolvimento de um perfil onde se acentua uma regulação de pendor mais burocrático e muito assente em instrumentos e referenciais codificados, passa a constituir-se como um ponto crítico, no sentido de este deixar pouco espaço para a lógicas de deliberação orientadas para a ponderação de outras dimensões, nomeadamente as de natureza fenoménica (Lopez, 2004).

Pela referência breve e panorâmica a estas observações críticas que permeiam hoje o debate em torno do empreendimento bioético, aquilo que desde já se constata é que esta é uma discussão em aberto e, sobretudo, com bastante actualidade, e isto sob múltiplos pontos de vista. De facto, e se designadamente nos ativermos nos aspectos relativos à própria 
constituição das já referidas CES (que se afirmam como os espaços de deliberação privilegiados nas instituições de saúde), percebe-se que algumas questões críticas podem também aflorar, nomeadamente as que se referem, desde logo, às próprias características destas estruturas.

Com efeito, considerando aquilo que são as suas características fundamentais, verifica-se que estas estruturas acabam por estar fortemente marcadas por um perfil bastante orientado para o âmbito da experimentação médica e para os dilemas da prática clínica ${ }^{5}$. Aliás, o Decreto-Lei que, no contexto nacional, enquadra e regula as comissões de ética (Decreto-Lei nº7/95, de 10 de Maio) coloca aí mesmo o seu enfoque, o que significa que a abordagem imputada às CES acaba por fazer associar o entendimento da investigação científica em saúde ao modelo da investigação clínica e biomédica. É uma característica que, no entanto e paradoxalmente, colide com a assunção plena dos pressupostos da multidisciplinariedade e do pluralismo que estão subjacentes às orientações preconizadas relativamente à natureza e composição das comissões de ética, nomeadamente pela própria Unesco.

Num certo sentido, tal não é completamente surpreendente, isto se nos ativermos aos particularismos do processo de institucionalização da bioética em Portugal (Neves, 1995), na medida em que, com a excepção de algumas iniciativas "precoces" no contexto nacional em particular a criação, em 1990, do Conselho Nacional de Ética para as Ciências da Vida (CNECV), constituindo-se como órgão independente funcionando junto à Presidência do Conselho de Ministros, assim como a existência dispersa e exígua, no decurso da segunda metade dos anos 1980, de algumas (poucas) comissões de ética assistencial a funcionar por via da iniciativa isolada dos hospitais que as promoveram (Idem) - o facto é que a reflexão e a deliberação ética institucionalmente organizada só começou a ter expressão a partir de meados dos anos 1990, altura em que o já referido Decreto-Lei institui a obrigatoriedade de todas as instituições de saúde, públicas ou privadas, criarem as suas CES.

Mas até esse momento, aquilo que efectivamente se verificou foi, por um lado, um movimento que gradualmente fez deslocar a bioética da academia para o contexto clínico (através da iniciativa de alguns centros de reflexão sobre matérias da bioética) e, por outro, o

\footnotetext{
${ }^{5}$ Veja-se, em especial, o ponto 2 do Artigo $1^{\circ}$ que define o âmbito das próprias CES: “Às CES cabe zelar pela observância de padrões de ética no exercício das ciências médicas, por forma a proteger e garantir a dignidade e integridade humanas, procedendo à análise e reflexão sobre temas da prática médica que envolvam questões de ética”.
} 
aparecimento relativamente "espontâneo" e crescente de comissões de ética hospitalares, muito focadas na análise de projectos de ensaios clínicos de medicamentos ${ }^{6}$. De referir que neste último caso, e seguindo a linha de reflexão de Neves (1995) sobre a crescente importância das Comissões de Ética, particularmente nos hospitais centrais universitários (contexto onde normalmente se realiza intensa investigação científica), "é lícito pensar que na sua origem está a pressão da indústria farmacêutica que exige que os protocolos a assinar tenham o parecer da Comissão de Ética. Aliás, foi precisamente este tipo de exigência que determinou a criação da grande maioria das Comissões de Ética em Portugal. Ou seja, estas surgiram não tanto por uma necessidade sentida no interior da unidade de cuidados de saúde mas por pressão vinda do exterior; não tanto por uma urgência ética mas por uma necessidade legal" (Idem).

Tendo estes elementos em consideração, constata-se, então, que o processo de institucionalização da bioética em Portugal acaba por estar muito vinculado ao protagonismo da investigação clínica e também ao predomínio dos conflitos éticos decorrentes da assistência hospitalar ${ }^{7}$, o que significa que o próprio âmbito da bioética acaba por denotar uma amplitude relativamente circunscrita. No caso concreto que aqui nos interessa - a deliberação ética sobre projectos de investigação em saúde -, esta circunstância acaba por potenciar um tipo de delimitação que é, seguramente, pouco adequado, na medida em que a saúde se tem constituído como um campo de estudo crescentemente transversal, designadamente nos domínios disciplinares externos às ciências da saúde. A constatação deste facto faz solicitar, por si só, a premência de uma efectiva multidisciplinaridade na sua composição, mas, acima de tudo, uma ampla pluralidade na forma de equacionar os pressupostos da ética da investigação, dado que muita da investigação (igualmente relevante

\footnotetext{
${ }^{6}$ Esta realidade das Comissões de Ética hospitalares ocuparem o essencial da sua acção, em paralelo com as problemáticas inerentes à ética assistencial, em torno da apreciação de projectos de ensaios clínicos foi algo que aconteceu até 2005, altura em que se concretizou a transposição de uma Directiva comunitária relativamente à aplicação das boas práticas clínicas na condução dos ensaios clínicos de medicamentos de uso humano, e que deu lugar a uma Lei que cria a figura da Comissão de Ética para a Investigação Clínica (CEIC). Esta estrutura passou, a partir de então, a ocupar-se, em exclusivo, da apreciação dos ensaios clínicos.

${ }^{7}$ Naturalmente que não advogo que estas características são, em si mesmas, desajustadas. Em matérias que remetem para fundamentos científicos e técnicos das ciências biológicas ou para situações dilemáticas no contexto da prestação dos cuidados de saúde em que os profissionais (e o médico e particular) são os protagonistas, os pareceres de índole ética fundados neste tipo de configuração têm toda a pertinência. O que o argumento procura destacar é apenas a ideia de que este tipo de percurso da Bioética não foi inócuo nos seus efeitos, particularmente quando tende a vincular a reflexão bioética à visão e aos pressupostos do tipo de investigação desenvolvido no âmbito das ciências da vida.
} 
e necessária) não partilha das características do modelo ético da investigação clínica e biomédica.

\section{Sobre a apreciação ética dos projectos de investigação: alguns elementos para uma reflexão situada}

Mas e no caso particular da CES da ARSLVT, qual parecer ser o panorama, ou dito de outro modo, o que é que a actividade da secção de investigação desta comissão tende a denotar em matéria de apreciação ética dos projectos de investigação? E particularmente quanto aos projectos disciplinarmente provenientes das ciências sociais?

De facto, e de resto como já anteriormente referido, a CES é um órgão colegial e multidisciplinar e assume uma natureza de órgão consultivo do Conselho Directivo da ARSLVT e dos Agrupamentos de Centros de Saúde (ACES) em matéria de ética assistencial e de investigação. Nessa conformidade, esta comissão analisa e reflecte eticamente sobre questões que lhe sejam suscitadas tanto no domínio assistencial como no domínio de investigação, seja por sua iniciativa, ou por solicitação do Conselho Directivo da ARSLVT e dos ACES, dela emitindo parecer, se for considerado adequado ${ }^{8}$. O seu âmbito de actuação reporta-se às unidades de cuidados não hospitalares da região embora também desenvolva um trabalho de articulação e cooperação com outras comissões de ética, nomeadamente com as CES hospitalares existentes.

Em matéria de composição ${ }^{9}$ e funcionamento a CES está, portanto, organizada em duas secções (Ética de investigação e Ética Assistencial) e apesar de a sua constituição reflectir um carácter plural, há, ainda assim, uma notória predominância médica. Actualmente (nomeadamente desde Julho de 2015, correspondendo esta data ao início do seu segundo triénio de actividade) esta comissão é composta por 15 (quinze) membros (sete membros por cada subcomissão e um Presidente). A secção da ética assistencial conta com dois médicos de Medicina Geral e Familiar (MGF), um médico "hospitalar"10, um teólogo (que é, simultaneamente, médico "hospitalar" aposentado), um jurista/enfermeiro, uma enfermeira e um sociólogo. A secção da ética de investigação conta com três médicos de

\footnotetext{
8 http://www.arslvt.min-saude.pt/pages/134

${ }^{9}$ http://www.arslvt.min-saude.pt/pages/136

${ }^{10}$ Esta designação serve apenas para sinalizar que se trata de médicos cuja especialidade é de âmbito hospitalar, diferenciando-se, assim, dos médicos de MGF cuja especialidade se desenvolve no contexto dos cuidados de saúde primários e não no âmbito dos cuidados hospitalares.
} 
MGF, dois médicos "hospitalares", uma enfermeira e uma Jornalista.

Já no que diz respeito ao desenvolvimento da sua actividade, designadamente ao nível da elaboração de pareceres face às propostas apresentadas junto da ARSLVT, é de referir que esse trabalho tende a ocorrer dentro de um prazo definido (o prazo de emissão de pareceres e que, aliás, consta no próprio regulamento interno da $\mathrm{CES}^{11}$, é de 60 dias a contar da distribuição dos projectos) sobre a observância dos padrões éticos.

$\mathrm{Na}$ apreciação ética dos protocolos de investigação, tendem a assumir preponderância, entre outros aspectos importantes, os quatro princípios éticos que são directamente tributários do principialismo e que têm moldado uma parte importante do pensamento ético, não obstante se poder argumentar que o mesmo integra, eclecticamente, várias outras perspectivas e modelos, nomeadamente as que se ligam a uma matriz mais europeia (Neves, 1995; Cascais 2015).

Tal como já referido, os princípios éticos principais são o da Autonomia (respeitar as pessoas nas tomadas de decisão, na realização das suas escolhas quanto aos objectivos pessoais e nas acções conformes a essa decisão); o da Beneficiência (relativo aos efeitos positivos e necessários para a promoção do bem-estar e direitos dos participantes nos processos de investigação); o da não maleficiência (a obrigação de não causar dano a outra pessoa, ponderando bem o rácio entre riscos e benefícios); e o da justiça distributiva (relativo à ponderação e partilha de riscos, benefícios e custos associados aos cuidados de saúde).

Mas antes mesmo de nos determos sobre as principais características relativas ao teor da apreciação dos projectos e das suas respectivas deliberações, importa ter alguma noção prévia do próprio processo, nomeadamente no que diz respeito aos requisitos formais que são exigidos para efeitos de elegibilidade dos projectos em termos da sua apreciação ética. A este propósito, a grelha a que se reporta a tabela 1 procede a uma síntese dos critérios que, numa lógica sequencial (a transição da coluna A até à Coluna F), justificam a submissão dos projectos à apreciação da CES.

11 Vide Artigo $17^{\circ}$, ponto 1 do regulamento interno da CES. http://www.arslvt.min-saude.pt/pages/137 
Tabela 1 - Critérios de admissibilidade

\begin{tabular}{|c|c|c|c|c|c|}
\hline $\mathbf{A}$ & B & $\mathbf{C}$ & D & $\mathbf{E}$ & $\mathbf{F}$ \\
\hline $\begin{array}{l}\text { Envolve utentes } \\
\text { e/ou profissionais } \\
\text { de saúde da } \\
\text { ARSLVT? }\end{array}$ & $\begin{array}{l}\text { É um estudo que } \\
\text { ainda não se } \\
\text { iniciou? }\end{array}$ & $\begin{array}{l}\text { É um estudo de } \\
\text { investigação? }\end{array}$ & \begin{tabular}{|l|} 
É um estudo de \\
investigação com \\
seres humanos?
\end{tabular} & $\begin{array}{l}\text { Implica utilização } \\
\text { de dados } \\
\text { pessoais? }\end{array}$ & $\begin{array}{l}\text { Cumpre com os } \\
\text { quesitos das } \\
\text { instruções de } \\
\text { submissão de } \\
\text { propostas pela } \\
\text { CES da } \\
\text { ARSLVT? }\end{array}$ \\
\hline $\begin{array}{l}\text { Se a resposta for } \\
\text { sim a qualquer } \\
\text { das perguntas das } \\
\text { linhas seguintes } \\
\text { passe para a } \\
\text { coluna B }\end{array}$ & $\begin{array}{l}\text { Se a resposta for } \\
\text { sim a qualquer } \\
\text { das perguntas das } \\
\text { linhas seguintes } \\
\text { passe para a } \\
\text { coluna C }\end{array}$ & $\begin{array}{l}\text { Se a resposta for } \\
\text { sim a qualquer } \\
\text { das perguntas das } \\
\text { linhas seguintes } \\
\text { passe para a } \\
\text { coluna D }\end{array}$ & $\begin{array}{l}\text { Se a resposta for } \\
\text { sim a qualquer } \\
\text { das perguntas das } \\
\text { linhas seguintes } \\
\text { passe para a } \\
\text { coluna E }\end{array}$ & $\begin{array}{l}\text { Se a resposta for } \\
\text { sim a qualquer } \\
\text { das perguntas das } \\
\text { linhas seguintes } \\
\text { passe para a } \\
\text { coluna F }\end{array}$ & $\begin{array}{l}\text { Se a resposta for } \\
\text { sim a todas as } \\
\text { perguntas das } \\
\text { linhas seguintes } \\
\text { preenche os } \\
\text { critérios de } \\
\text { submissão às CES } \\
\end{array}$ \\
\hline $\begin{array}{l}\text { - A investigação } \\
\text { corre na área } \\
\text { geográfica da } \\
\text { ARSLVT? } \\
\text { - A investigação } \\
\text { envolve utentes e } \\
\text { ou profissionais } \\
\text { de saúde das } \\
\text { instituições de } \\
\text { saúde tuteladas } \\
\text { pela ARSLVT, } \\
\text { que não dispõem } \\
\text { de Comissões de } \\
\text { Ética para a } \\
\text { Saúde? } \\
\text { - A investigação } \\
\text { ocorre n um País } \\
\text { terceiro, envolve } \\
\text { investigadores da } \\
\text { ARSLVT e é } \\
\text { patrocinado } \\
\text { formalmente pela } \\
\text { ARS e obriga a } \\
\text { uma apreciação } \\
\text { ética no país de } \\
\text { origem? }\end{array}$ & \begin{tabular}{|l} 
- O pedido de \\
apreciação é \\
prévio ao início \\
do recrutamento? \\
- É um estudo \\
multicêntrico e o \\
pedido de \\
apresentação é \\
prévio ao \\
envolvimento de \\
utentes e/ou \\
profissionais da \\
ARSLVT?
\end{tabular} & $\begin{array}{l}\text { É um estudo que } \\
\text { se pode } \\
\text { considerar } \\
\text { cumprir os } \\
\text { critérios para ser } \\
\text { considerado como } \\
\text { dispondo do } \\
\text { potencial de gerar } \\
\text { ou contribuir para } \\
\text { um conhecimento } \\
\text { generalizável? }\end{array}$ & $\begin{array}{l}\text { - É um estudo que } \\
\text { envolve } \\
\text { investigação com } \\
\text { seres humanos } \\
\text { (ou material de } \\
\text { origem humana, } \\
\text { tal como: tecidos; } \\
\text { amostras) e o } \\
\text { investigador } \\
\text { interage } \\
\text { directamente com } \\
\text { seres humanos? } \\
\text { É um estudo que } \\
\text { se pode incluir } \\
\text { como: } \\
\text { - O estudo dos } \\
\text { mecanismos de } \\
\text { doença; } \\
\text { - As intervenções } \\
\text { terapêuticas } \\
\text { - As intervenções } \\
\text { farmacológicas, } \\
\text { de dispositivos } \\
\text { médicos ou de } \\
\text { técnicas cirúrgicas } \\
\text { (Ensaios clínicos); } \\
\text { - Estudos } \\
\text { observacionais e } \\
\text { comportamentais; } \\
\text { - A investigação } \\
\text { em resultados } \\
\text { (Outcomes } \\
\text { Research) e os } \\
\text { estudos dos } \\
\text { Serviços de Saúde } \\
\text { (Health Services } \\
\text { Research) }\end{array}$ & $\begin{array}{l}\text { - O investigador } \\
\text { obtém dados a } \\
\text { partir de uma } \\
\text { intervenção / ou } \\
\text { de uma interacção } \\
\text { com os utentes? } \\
\text { - O utilizador } \\
\text { utilizará dados } \\
\text { pessoais } \\
\text { identificáveis? }\end{array}$ & \begin{tabular}{|l|} 
O dossier de \\
submissão cumpre \\
com os critérios \\
de submissão da \\
ARS? \\
- Protocolo \\
- CV \\
- Folha de \\
Informação e \\
Consentimento \\
- Declaração de \\
Confidencialidade \\
- Modelo de \\
referenciação \\
- Declaração do \\
orientador \\
científico \\
- Declaração do \\
Director de \\
Serviço \\
- Cópia CNPD \\
- Compromisso de \\
Relatórios \\
Anual/Final \\
- Contracto \\
Financeiro
\end{tabular} \\
\hline
\end{tabular}

Fonte: CES-ARSLVT 
Como é bem patente pela informação exposta nesta grelha, nomeadamente na coluna $\mathrm{F}^{12}$, há um conjunto de elementos que se tornam indispensáveis para efeitos de instrução do processo que visa a produção de parecer da CES relativamente aos projectos de investigação que remetam para o acesso a dados e informações de utentes ou de profissionais abrangidos pela ARSLVT.

Podem, contudo, requerer isenção de apreciação os projectos que preencham alguns critérios específicos, concretamente se os dados:

$\rightarrow$ Existem e estão disponíveis ao público;

$\rightarrow$ Existem e não são identificáveis pela equipa de investigação

Os investigadores podem também requerer a isenção de apreciação de projectos de investigação que sejam promovidos por Instituições do Ministério da Saúde e que sejam desenhados para estudar, avaliar e monitorizar:

$\rightarrow$ O interesse público ou programas de acção de serviços;

$\rightarrow$ Procedimentos relativos à aplicação de programas de saúde ou actividades relacionadas com esses programas;

$\rightarrow$ Alterações aos procedimentos ou programas de saúde;

Estão ainda abrangidos por esta "excepcionalidade" os ensaios clínicos com medicamentos de uso humano, uma vez que essa competência está legalmente atribuída à CEIC, assim como os estudos de investigação com pareceres positivos de CES, com âmbito e competência similares aos da CES da ARSLVT.

Nas situações em que esta isenção de apreciação não se coloca, o percurso "normal" dos projectos pressupõe um conjunto de etapas que procura assegurar uma apreciação tão completa e célere quanto possível. Nesse sentido, e conforme se pode constatar pela figura 1, a etapa inicial da avaliação administrativa do processo de submissão dos projectos é crucial, dado que permite aferir se existem, ou não, os elementos documentais necessários para viabilizar a sua apreciação.

Assim, se a proposta estiver formalmente completa os processos são distribuídos pelo presidente da CES aos diferentes membros da comissão para estes elaborarem proposta de parecer que será, posteriormente, objecto de discussão e avaliação interpares antes de seguir para o Conselho Directivo da ARSLVT com uma proposta de

12 http://www.arslvt.min-saude.pt/pages/141 
deliberação. Caso os projectos não estejam completos, são solicitados aos investigadores os documentos em falta. Quando, por fim, estão reunidas todas as condições para a elaboração de parecer, este poderá ser positivo ou então, no caso de não remeter para uma deliberação negativa, pode dar lugar a um parecer condicionado, no sentido de este conter objecções que pressuponham algum tipo de clarificação por parte dos proponentes ou mesmo a reformulação de alguma lacuna que comprometa o cumprimentos dos requisitos éticos, designadamente ao nível da protecção da integridade, privacidade ou bem-estar dos potenciais participantes nas investigações. No primeiro caso, o investigador é informado de que, sob o ponto de vista da apreciação ética, a investigação tem condições de prosseguir. Já no segundo caso, informa-se o proponente do projecto da necessidade de reelaboração da proposta em conformidade com as objecções e fundamentos apresentados.

\section{Figura 1 - Esquema do percurso de um projecto proposto à CES da ARSLVT para produção de parecer}

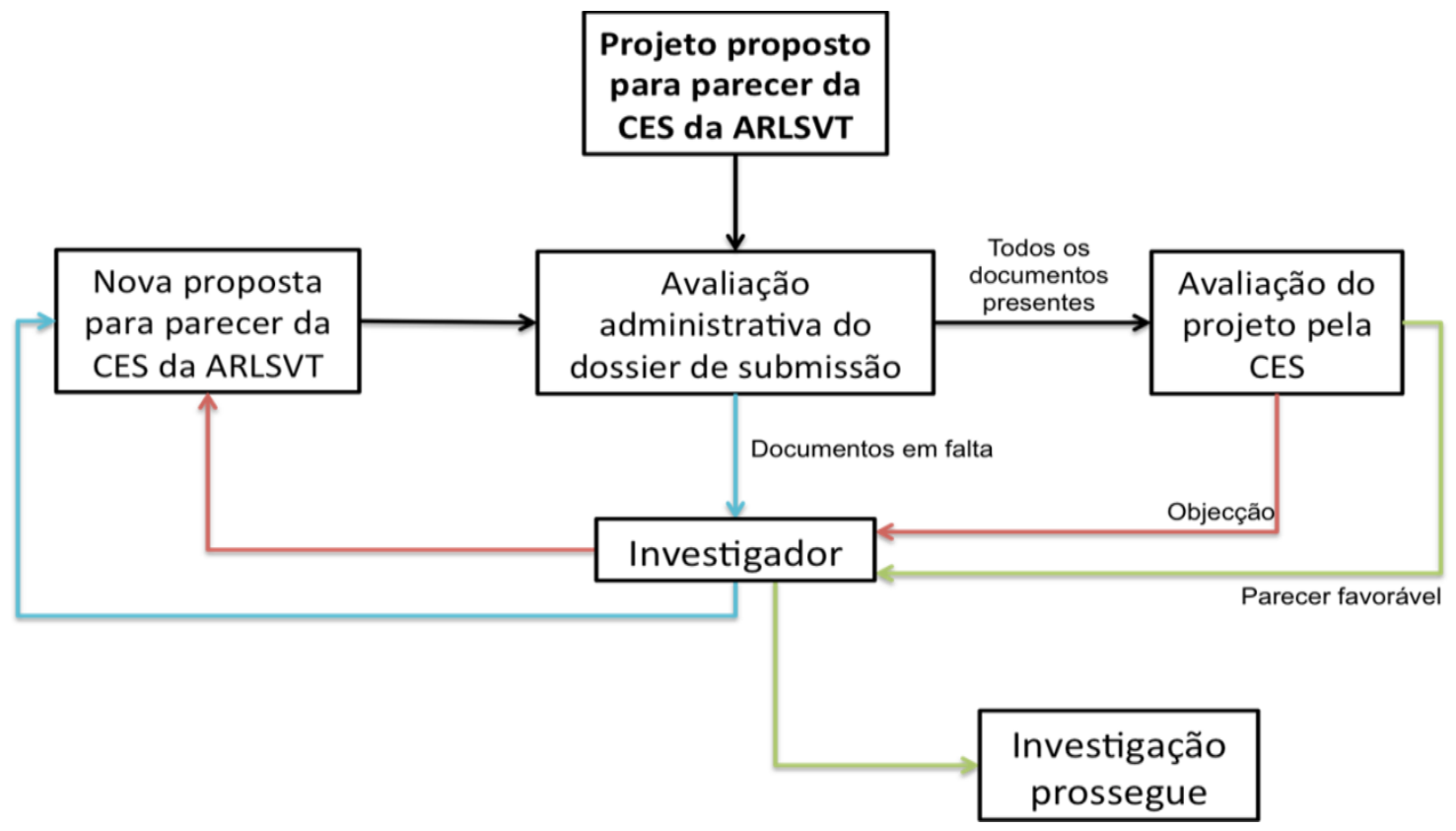

Após esta breve descrição processual, cabe agora determo-nos naquilo que é a actividade da CES em matéria de apreciação ética de projectos de investigação. 
Assim, e no decurso do seu primeiro triénio de actividade (o arco temporal que está aqui a ser analisado), constata-se um crescimento significativo dos estudos de investigação submetidos, sendo que na sua larga maioria são estudos da iniciativa dos investigadores, destacando-se de forma expressiva aqueles que são de índole académica (nomeadamente mestrados e doutoramentos). Assim, e no âmbito deste período, a CES produziu um acervo de 253 pareceres, apresentando uma distribuição onde claramente se destacam duas grandes áreas do conhecimento, concretamente as Ciências da Saúde (num total de 109 pareceres) e as Ciências Sociais (num total de 44 pareceres).

De facto, e tal como se pode constatar pela leitura da figura 2, verifica-se que em termos da proveniência dos projectos apresentados à CES a área do que aqui se designa de Ciências da Saúde é aquela que, talvez não surpreendentemente, assume maior expressão. Depois, e a par dos projectos provenientes das áreas disciplinares das Ciências Sociais, os projectos que assumem também alguma expressão são os estudos institucionais (fundamentalmente estudos de intervenção ou de melhoria da qualidade dos serviços de saúde), ou seja, aqueles que são promovidos por diversos organismos institucionais, sobretudo os que estão sob a tutela do próprio Ministério da Saúde. Embora com menor expressão, são também de referir os estudos promovidos pela Indústria Farmacêutica, os projectos referentes a cursos de especialização em Administração Hospitalar (e neste caso, aqueles que são concretamente promovidos pela Escola Nacional de Saúde Pública), e vários outros projectos dispersos por áreas distintas e com pouca expressão quantitativa no total deste acervo ${ }^{13}$.

De referir também que há um número não despiciendo de propostas que acabam, na prática, por não se formalizar, ficando apenas por um primeiro contacto onde os promotores dos projectos apresentam a ideia e procuram assegurar a disponibilidade da CES enquanto estrutura facilitadora para o desenvolvimento de projectos de investigação. Nestas situações a resposta da CES consiste na solicitação de apresentação formal da proposta com os respectivos requisitos documentais. Em todos

\footnotetext{
13 Nesta categoria de "Outros" estão englobados 3 projectos promovidos por investigadores provenientes das Ciências do Deporto, ao passo que os restantes 4 dizem respeito a projectos referentes à Engenharia Biomédica, Linguística, Bioestatística e Bioquímica.
} 
estes casos de projectos de que não se dispõe de informação, o que tal traduz é a efectiva ausência de envio de qualquer proposta por parte dos seus promotores.

Figura 2 - Proveniência científica/institucional dos projectos

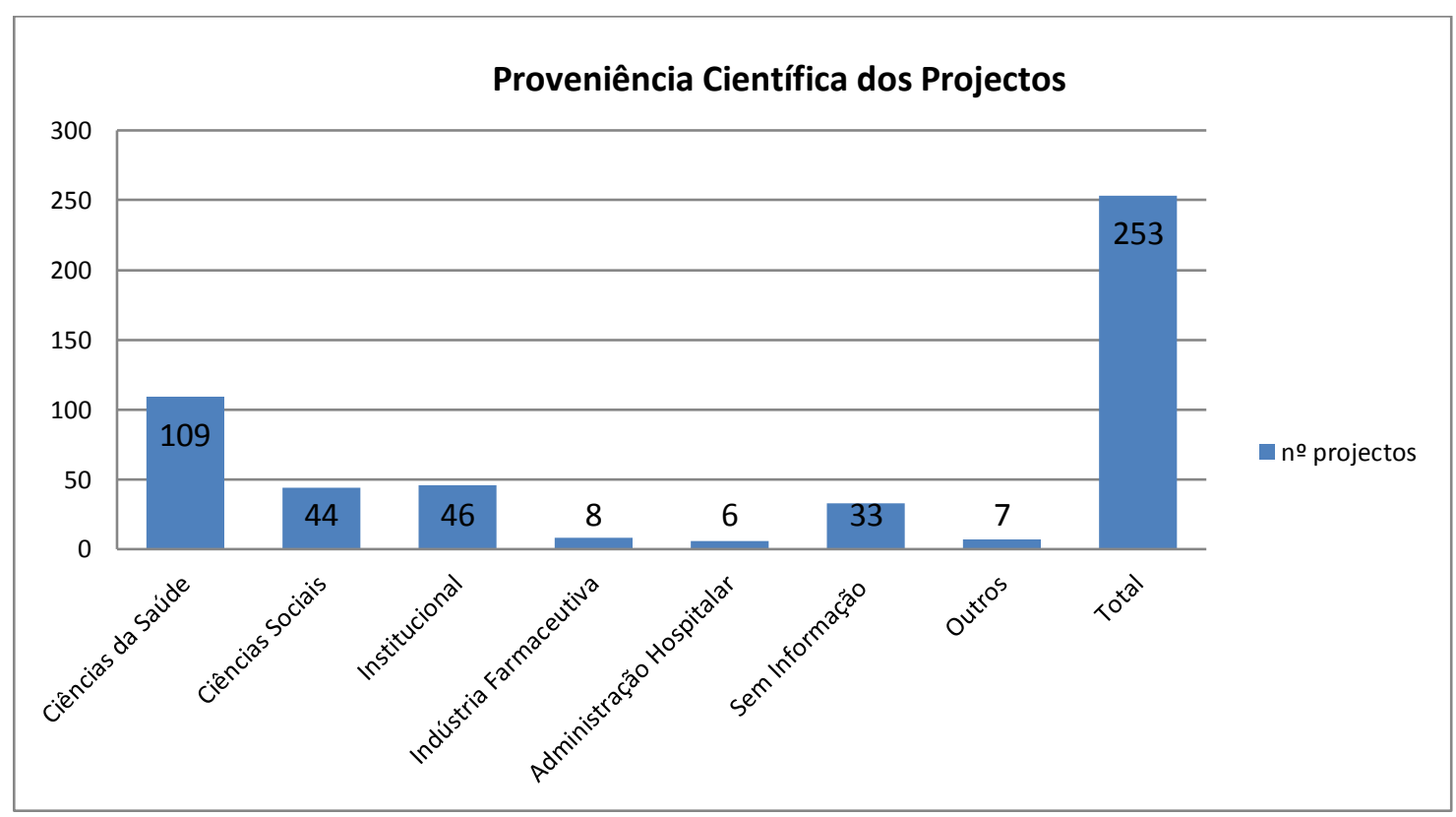

No que diz respeito aos projectos que são provenientes das Ciências da Saúde, e tal como se pode verificar pela figura 3 , aqueles que assumem uma maior predominância são os que são provenientes da área da Medicina (59 pareceres), seguido dos de Enfermagem (23 pareceres). No caso dos que se reportam à área da Medicina importa referir que mais até dos que têm um pendor académico (26 no total), existe um amplo conjunto de projectos que estão mais directamente ligados às actividades formativas dos internatos médicos (33 no total), particularmente no contexto da MGF. Já os restantes projectos de investigação (todos de âmbito académico) distribuem-se pela área da Saúde Pública, das Tecnologias da Saúde $^{14}$ e de várias outras áreas enquadráveis na saúde, nomeadamente ao nível de programas de mestrado em várias áreas aplicadas das ciências da saúde.

\footnotetext{
14 Neste caso, 5 dos 8 projectos académicos correspondem a trabalhos de investigação no âmbito dos cursos de licenciatura.
} 
Figura 3 - Subuniverso dos projectos de investigação provenientes das Ciências da Saúde

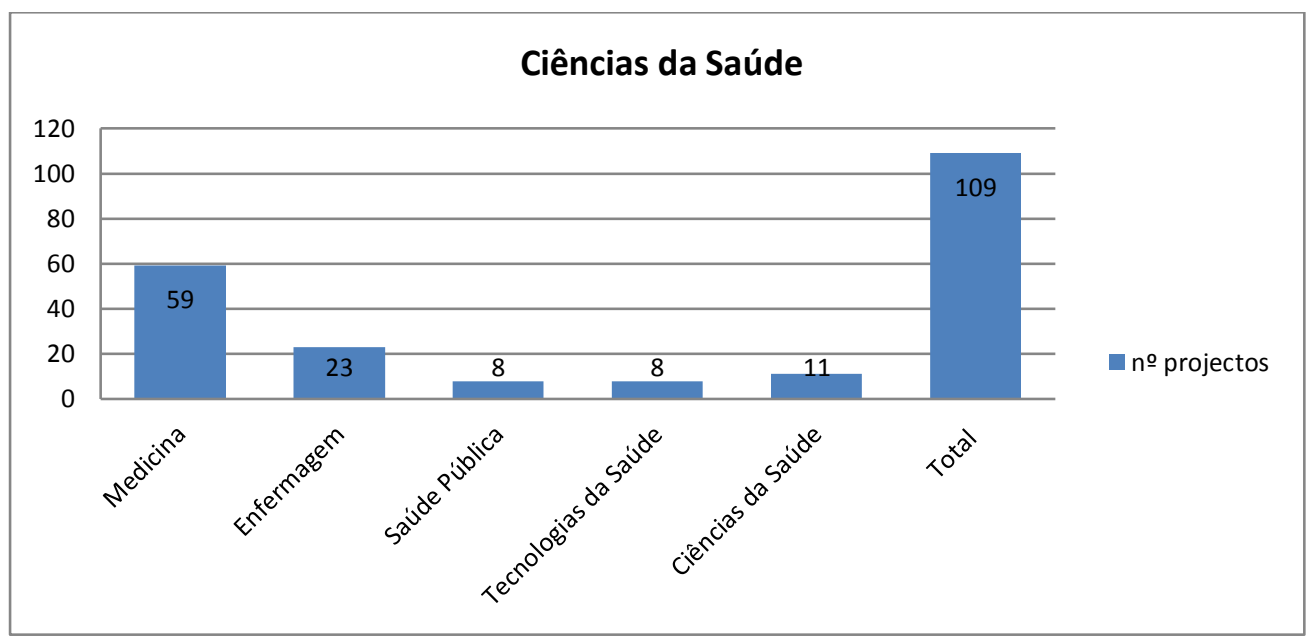

Considerando agora o subuniverso dos projectos de investigação (maioritariamente de pendor académico) que são provenientes das Ciências Sociais, a sua distribuição (cf. figura 4) reflecte um predomínio dos que se reportam à área disciplinar da Psicologia (19 no total), seguidos dos que são provenientes da Sociologia (7), Gestão (7), Antropologia (4), Economia (4), Serviço Social (2) e Geografia (1). Centrando-nos no caso específico dos projectos provenientes da Sociologia e da Antropologia (aqueles que, em absoluto, estão aqui em apreço), é de salientar que o conjunto destes projectos se distribui entre trabalhos académicos e projectos desenvolvidos no quadro das actividades de centros de investigação.

Figura 4 - Subuniverso dos projectos de investigação provenientes das Ciências Sociais

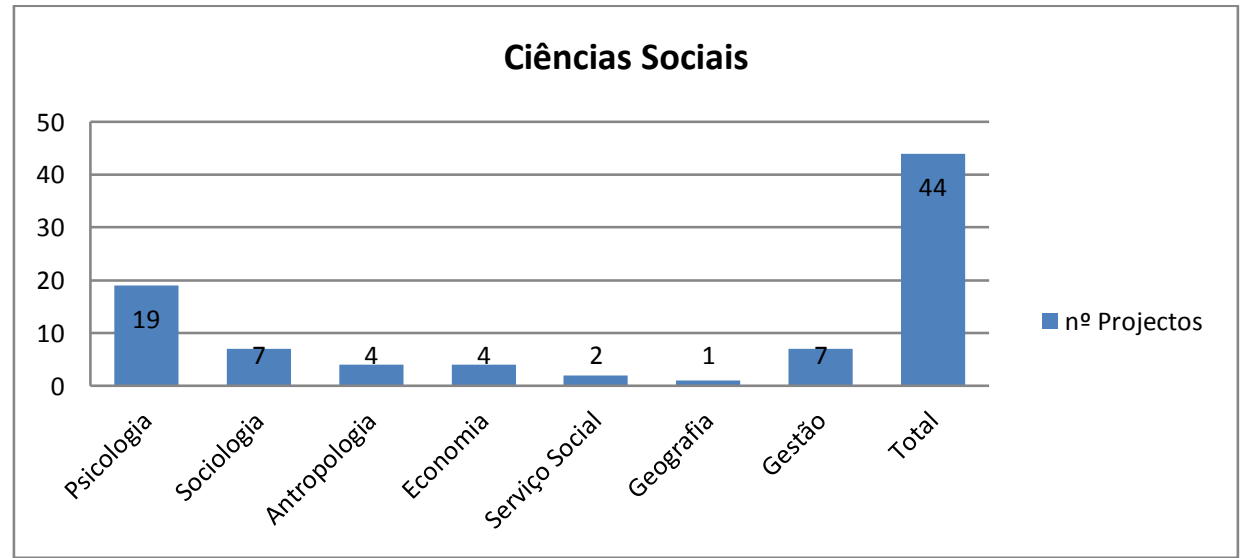


No caso dos projectos de Sociologia, importa referir que dois deles acabaram, na prática, por não dar lugar à formalização de qualquer proposta ou à apresentação de um protocolo. Correspondem a pedidos de alunos finalistas da licenciatura de Sociologia de duas instituições universitárias distintas para, num caso, a aplicação de um questionário aos utentes de um Centro de Saúde e, no outro, para autorização de início de trabalho de campo junto de mulheres com diagnóstico de depressão. Como sempre acontece nestas circunstâncias foi solicitado pela CES a apresentação formal da proposta com os respectivos requisitos documentais. Não tendo havido qualquer retorno nesse sentido, estas propostas em concreto acabaram por não dar lugar a qualquer apreciação ética por parte desta estrutura. Acresce a estes casos dois outros projectos - neste caso correspondendo a investigações de doutoramento - que foram objecto dos já supra mencionados critérios de isenção de apreciação, nomeadamente por as respectivas orientações metodológicas remeterem para a aplicação de questionários a diferentes tipos de dirigentes da Administração Pública relativamente à sua percepção quanto à implementação de modelos políticos e organizacionais em diferentes domínio do sector público da saúde. Assumiu-se, assim, que o envolvimento destes profissionais nestes processos de recolha de informação pressupunha um consentimento tácito e que não havia lugar à recolha de dados pessoais identificáveis.

Dito isto, somente no caso de três projectos é que houve lugar a uma apreciação ética das propostas. Dois desses casos correspondem a projectos desenvolvidos no quadro das actividades de centros de investigação, ao passo que o outro reporta-se a uma investigação enquadrada no âmbito de um Programa de Estágios Profissionais na Administração Pública Central (PEPAC).

Na primeira situação, ambos os projectos deram lugar a uma primeira apreciação que produziu pareceres favoráveis condicionados. Ou seja, pareceres positivos mas acompanhados da solicitação de esclarecimentos sobre aspectos mais operacionais da metodologia e sobre aspectos processuais. Num dos pareceres, entendeu-se necessário obter uma maior clarificação acerca dos aspectos práticos relativos às formas de acesso à informação dos utentes (até porque se falava da figura de "investigadores locais" enquanto mediadores privilegiados junto de uma população particular (imigrante), assim como se solicitou a adequação do cronograma das actividades a prazos consentâneos com 
a própria processualidade do trabalho de apreciação da CES, bem como uma declaração de compromisso de entrega de relatório final do estudo. No outro parecer foram igualmente solicitados esclarecimentos, mas neste caso relativos ao fornecimento de elementos clarificadores da fundamentação teórica e metodológica do estudo (dado que o protocolo enviado originalmente era, a esse nível, muito sintético), mas também relativamente à utilização de um modelo de consentimento informado e, tal como no caso anterior, a respectiva adequação do cronograma de actividades e a declaração de compromisso de entrega do relatório final à CES.

Face ao envio destes pareceres, os respectivos promotores dos projectos responderam ora clarificando e fundamentando a natureza das suas opções metodológicas, ora facultando os elementos solicitados; tanto os de carácter mais processual, mas também (num dos casos) um protocolo mais detalhado no seu enquadramento e justificação científica. De referir que no segundo caso que foi acima mencionado, os promotores do projecto justificaram a não necessidade de um modelo de consentimento informado a acompanhar o questionário, dado tratar-se de questionário anónimo, de autopreenchimento e de entrega voluntária. Em resposta, a CES entendeu estarem clarificadas todas as dúvidas e reservas, pelo que foi rapidamente emitido um parecer final positivo, com vista à viabilização, de um ponto de vista ético, das investigações em causa.

Relativamente ao projecto de investigação enquadrado no âmbito de um Programa de estágios Profissionais, o mesmo suscitou várias objecções, concretamente as que remetem para a necessidade de vários elementos de fundamentação quanto às opções empíricas e operacionais da própria investigação. A justificação da população seleccionada, a forma como estaria prevista a colaboração das unidades de saúde e dos profissionais, as modalidades de recrutamentos dos doentes em cada unidade de saúde, a responsabilidade do recrutamento e do cumprimento da obtenção do consentimento informado, mas também a disponibilização prévia do plano de análise estatística a desenvolver no estudo. Estas objecções, assim como a solicitação de alguns outros elementos processuais (declarações, ajuste de cronograma, $\mathrm{CV}$, etc.) foram endereçados ao proponente, contudo não houve, posteriormente, qualquer retorno em termos de justificação ou resposta às objecções. 
Já no que diz respeito aos projectos de Antropologia, é de referir que uma das propostas (uma investigação de mestrado) não deu lugar à formalização de qualquer proposta ou à apresentação de um protocolo; um dos projectos apresentados insere-se no quadro das actividades de um centro de investigação; e os outros dois correspondem a investigações de mestrado (na área da antropologia médica).

$\mathrm{Na}$ situação referente ao projecto desenvolvido no quadro de um centro de investigação, este deu lugar a um parecer favorável condicionado. As objecções foram maioritariamente de natureza processual (alguns elementos documentais em falta como, por exemplo, a necessidade de uma declaração do Director Executivo do ACES onde o estudo se iria desenvolver), mas também de carácter metodológico. Neste aspecto, as objecções não se reportam à natureza da orientação qualitativa do estudo nem às técnicas contempladas para efeitos de recolha de informação, mas centram-se em dois aspectos particulares. Por um lado, a inclusão de um modelo de consentimento informado como requisito documental que deve acompanhar as entrevistas a realizar junto da população seleccionada e, por outro, a recusa de o processo de recrutamento dos sujeitos para as entrevistas tenha como contrapartida para os próprios a entrega de um voucher com um determinado valor monetário. Estas objecções acabaram por ser acolhidas pelos proponentes, dando assim lugar à produção de uma deliberação favorável por parte da CES.

No caso das duas propostas que correspondem a investigações de mestrado, as mesmas deram lugar a pareceres distintos nas suas deliberações finais. Num deles foi emitido um parecer favorável, apesar de ter sido antecedido por um parecer intermédio que apresentava algumas dúvidas e reservas, e no outro a emissão de parecer ficou condicionada ao envio de vários elementos documentais em falta, mas sobretudo à clarificação de muitas dúvidas quanto a opções operacionais mas também fundamentações mais substantivas quanto aos próprios objectivos da pesquisa.

Na primeira situação, o parecer intermédio centrou-se em duas dimensões principais; fundamentos técnicos e científicos de algumas opções metodológicas, e questões éticas relacionadas com o processo de recrutamento dos participantes e respectiva salvaguarda da confidencialidade dos dados pessoais dos entrevistados. No âmbito da primeira dimensão foram solicitadas clarificações quanto à selecção das variáveis em estudo, quanto à fundamentação da utilização dos questionários para uma das populações a 
envolver no estudo (crianças) e quanto à estratégia prevista para a análise dos dados. Quanto à segunda dimensão as várias dúvidas específicas que foram apresentadas entroncam todas na questão de fundo do processo de recrutamento e da explicitação dos procedimentos a adoptar ao nível do cumprimento dos requisitos da confidencialidade dos dados pessoais. Em resposta, os proponentes clarificaram todos os procedimentos e explicitaram todas as garantias de boas práticas de investigação (salientando, neste caso, as próprias normas e princípios éticos dos trabalhos académicos da instituição onde se enquadra a pesquisa em questão), assim como providenciaram elementos (decorrentes do próprio quadro teórico da investigação) que deram cabal justificação acerca da pertinência e da adequação das opções metodológicas. Todos os elementos e argumentos foram considerados suficientes para a elaboração de um parecer final favorável.

Já quanto à segunda proposta que aqui foi referida, a mesma deu lugar a um parecer onde foram solicitados vários elementos documentais necessários para que o pedido ficasse formalmente mais adequado aos requisitos exigidos (nomeadamente ao nível de declarações; do orientador da pesquisa e da Directora do ACES onde se pretendia que a pesquisa fosse realizada), mas também elementos de fundamentação científica para melhor aferir os objectivos do estudo, a definição da população e da amostra. Também se salientou a necessidade de um consentimento informado e uma justificação que clarificasse a necessidade de acesso aos dados do Hospital da área geográfica de referência da população a estudar. Estas várias dúvidas e reservas foram enviadas aos promotores do projecto, contudo não deu lugar ao retorno de qualquer esclarecimento ou reformulação.

Apresentada esta descrição relativamente ao conjunto das propostas enquadráveis nas áreas disciplinares da Sociologia e da Antropologia, que ilações podem, então, ser tiradas quanto aos processos de deliberação de pareceres, considerando que os projectos de investigação das ciências sociais têm características que, naturalmente, não são inteiramente comparáveis à investigação de pendor clínico e biomédico?

Assim, e mesmo considerando a importante ressalva de que a relativa exiguidade do volume de pareceres sobre projectos de investigação de ciências sociais não nos autoriza a desenvolver considerações peremptórias e generalizáveis, não deixa, ainda assim, de ser muito útil a sinalização de alguns aspectos recorrentes que podem concorrer para alguma problematização desta questão. 
Em primeiro lugar não deixa de ser importante referir a existência de alguns projectos que, por ausência de envio de informação documental, acabam por não dar origem à formalização de qualquer submissão de apreciação. Confrontados com o requisito da apresentação formal de uma proposta completa, alguns dos proponentes (inclusive na área das ciências sociais) acabam por não desencadear esse mesmo processo de submissão. O que tal circunstância parece denotar é a existência de algum grau de desconhecimento e de eventual estranheza face às exigências formais colocadas por uma estrutura de ética institucionalizada. É uma hipótese que, com efeito, poderá ter alguma plausibilidade, isto se tivermos em atenção que uma parte considerável das objecções que constam nos pareceres são, justamente, de natureza processual. Ou seja, não são raras as situações em que, do ponto de vista documental, os projectos apresentados carecem de alguns elementos, o que significa que ainda não está suficientemente incorporado junto da larga maioria dos proponentes a concepção de que a produção de pareceres remete para um processo regulatório já institucionalizado e, como tal, com exigências formais específicas.

Uma outra questão, certamente mais sensível e problemática, é a que diz respeito à apreciação dos projectos na vertente dos seus aspectos científicos, dado que em bom rigor essas questões remetem especificamente para o enquadramento académico das investigações e da respectiva avaliação e validação por parte da comunidade científica. No entanto, não deixa de haver quem argumente que a não consideração dos aspectos formais científicos podem levar a que se descure a possível existência de "má ciência" o que, deste ponto de vista, tende a ser visto como sinónimo de investigação antitética. A presumível falta de qualidade científica das investigações torna-se, assim, uma preocupação que pode, por conseguinte, fazer emergir um claro conflito de papéis de natureza mais institucional no sentido em que essa apreciação pode colidir com a validação académica das propostas e, desse modo, com a própria legitimidade das respectivas comissões que são responsáveis pela validação prévia das respectivas componentes científicas dos projectos de investigação.

Se para a análise desta questão nos circunscrevermos ao conjunto dos pareceres de que nos ocupámos, diríamos que esse potencial conflito acaba por ser claramente mais latente do que manifesto, na medida em que nas situações em que se solicitaram clarificações 
sobre aspectos metodológicos ou sobre a própria fundamentação das propostas, esses pedidos foram sempre no sentido de se ficar a conhecer melhor os pressupostos subjacentes às opções apresentadas no âmbito dos protocolos e não tanto na perspectiva de rebater as orientações teóricas ou de assumir a sua mera inconsistência. No fundo, esta questão acabou por surgir porque em várias situações os protocolos se revelaram relativamente sintéticos e enunciativos, não explicitando os fundamentos das várias opções identificadas.

Mas já nas situações em que esses pedidos de clarificação se estendem à solicitação da apresentação prévia do plano de análise estatística ou da justificação das variáveis do estudo, tal parece configurar uma certa ingerência em aspectos científicos mais substantivos. Para além de tal parecer traduzir um entendimento relativamente normalizado da própria investigação, como se esta se desenvolvesse sempre numa sequência linear e pré-definida de etapas em que os procedimentos de análise são entendidos numa concepção consentânea com a lógica hipotético-dedutiva do método experimental, essas mesmas clarificações remetem para um nível de discussão de fundamentos científicos cuja especificidade ultrapassa os critérios de ponderação ética, a menos que, naturalmente, o tipo de dados a obter e as suas respectivas formas de obtenção comprometam as mais elementares garantias de anonimização da informação relativa aos participantes das investigações.

Todavia, o aspecto que, sem margem para grandes dúvidas, se revela como efectivamente crucial e ubíquo na lógica da apreciação ética dos projectos é o que se refere ao consentimento informado, um instrumento formal que é assumido como um dos grandes garantes do respeito dos princípios normativos já enunciados, nomeadamente o da autonomia. Considerando o teor dos pareceres, este é precisamente o aspecto mais transversal e estruturante, dado que as questões directamente ligadas às suas formas da sua obtenção, bem como os procedimentos e mecanismos de salvaguarda da confidencialidade e privacidade dos dados pessoais, são a preocupação mais recorrente no exercício da deliberação ética. Assim, e embora não se tenha propriamente verificado qualquer tipo de "atropelo" às especificidades das investigações metodologicamente ancoradas na pesquisa qualitativa, o facto de existir um grande ênfase no consentimento informado faz salientar a centralidade do pressuposto da vulnerabilidade dos sujeitos, ou 
seja, o entendimento precaucionário que presume a necessidade de protecção dos participantes (através, justamente, do consentimento informado) por receio dos impactos negativos da investigação (Nunes, 2011).

Por fim, importa ainda mencionar, considerando a prática do processo deliberativo da CES, em geral, e do conjunto seleccionado dos processos de Sociologia e de Antropologia, em particular, que a questão do tempo de resposta desta comissão relativamente aos projectos que são submetidos à sua deliberação ética, não só é coerente com o compromisso assumido no seu próprio regulamento interno quanto ao prazo de emissão de pareceres (60 dias a contar da data da sua distribuição), como acaba por ser contrastante com algumas outras experiências que, em virtude dos excessos de burocratização institucional, conduzem a práticas de deliberação muito dilatadas no tempo. Nessas situações, as perturbações e os efeitos perversos daí decorrentes podem, na prática, acabar por inviabilizar o desenvolvimento regular da investigação, sobretudo quando esta se desenvolve no quadro de programas de financiamento que pressupõem, nos termos da sua contratualização, o vínculo formal a compromissos muito objectivos relativamente a prazos para a concretização das várias etapas das pesquisas (Monaghan, O’Dwyer, Gabe, 2013)

\section{A Sociologia no contexto da Ética Institucional: Algumas reflexões e considerações finais}

Tomando como pretexto a experiência de colaboração na CES-ARSLVT para a concretização deste breve exercício reflexivo, um aspecto que, com efeito, se destaca é o que se prende com a constatação de que a crescente institucionalização da ética no domínio da saúde é um claro reflexo de que este campo tem vindo a estabelecer um panorama regulatório que é cada vez mais incontornável nos próprios processos de desenvolvimento do conhecimento científico.

No que diz especificamente respeito ao modo como se tem concretizado a incorporação das ciências sociais neste mesmo processo, saliente-se que esta é, factualmente, recente e limitada na sua abrangência, sendo também de referir que a natureza do próprio enfoque deliberativo tende ainda a ser pouco permeável a critérios de avaliação ética desvinculados do modelo da investigação clínica (Orfali, DeVries, 2010; Marques, 2015; Cascais, 2015). 
Nesta medida, e procurando dar uma utilização operatória à classificação proposta por Raymond De Vries (cf. Orfali, DeVries, 2010; Marques, 2015) para dar conta da relação diferenciada e potencialmente tensa entre estas duas disciplinas - a Sociologia na Bioética ou a Sociologia da Bioética ${ }^{15}$ - diria, tendo em conta a experiência de participação que aqui é reportada, que esta configura uma realidade na qual a sociologia desempenha um papel fundamentalmente consultivo e colaborativo no empreendimento bioético (Sociologia na Bioética), uma vez que o contributo que é efectivamente desenvolvido tem-se consubstanciado na avaliação da adequação dos projectos às normas estabelecidas.

Neste sentido, e considerando o pequeno acervo de processos, e respectivas deliberações, que aqui se tomaram como a base empírica deste exercício reflexivo, podemos considerar que aquilo que a análise desenvolvida nos mostra é, por um lado, uma normalização dos processos de investigação na área da saúde, no sentido de ser notória a procura da adequação dos projectos aos requisitos e exigências formais estabelecidos por uma estrutura como a CES, mas por outro lado, pode-se também considerar que os processos de deliberação podem, em alguns casos, tornar bastante fluidas e algo sobreponíveis as fronteiras entre apreciação científica e ética (com riscos de potenciais ingerências em aspectos substantivos cujas implicações éticas podem ser, se não inexistentes, pelo menos questionáveis). Acresce ainda a este aspecto a existência de uma lógica de apreciação ética que tende a acentuar a primazia do consentimento informado enquanto modelo hegemónico cujos enunciados normativos estabelecem um tipo de regulação que nem sempre é inteiramente adequado a certas formas de investigação, como é nomeadamente o caso de estratégias de investigação qualitativa como a pesquisa de terreno ou a etnografia (Lopez, 2004).

Neste último caso - e apesar de, em bom rigor, os processos analisados não denotarem de uma forma explícita este tipo de tensão -, pode-se considerar que o essencial dessa potencial desadequação decorre do facto de estas estratégias se basearem em práticas fundadas em relações interpessoais e de exigirem um grau de profundidade maior nas relações de investigação como forma privilegiada de alcançar uma melhor compreensão da complexidade que caracteriza as realidades estudadas. Tal coloca, por conseguinte,

15 Modelo de crítica explícita relativamente aos próprios pressupostos da bioética. 
distintos desafios éticos, desde logo porque, por exemplo, o anonimato pode ser preterido, sobretudo se os próprios informantes pedirem a revelação da sua identidade, ou das suas histórias, tanto como forma de reconhecimento do seu contributo, como forma de recuperar alguma "voz" ou visibilidade em situações problemáticas da própria existência social dos sujeitos (Nunes, 2011). Há, por isso, que ter em conta que os protocolos estabelecidos entre informantes e investigadores poderão ser diferentes consoante os casos, as especificidades e a diversidade dessas relações.

Pensando em termos dos desafios que estas situações impõem para os próprios modelos da deliberação ética, destaca-se, assim, a importância de salvaguardar as especificidades da investigação sociológica (e antropológica) em saúde, designadamente ao nível da pluralidade dos seus objectos de estudo; ao nível da pluralidade metodológica (descentrar das metodologias quantitativas); assim como ao nível da consideração dos requisitos éticos na pesquisa qualitativa. Daqui decorre uma importante reflexão quanto aos limites das aspirações universalistas da bioética e quanto às dificuldades de transposição do modelo ético da investigação médica para as ciências sociais, não devendo a normatividade do modelo de protecção da integridade e privacidade dos sujeitos humanos ser dogmática, pois o pressuposto da vulnerabilidade dos participantes na investigação - como que sujeitos ao controlo e à acção discricionária dos que realizam a investigação e submetidos a procedimentos susceptíveis de pôr em risco a sua saúde ou a sua vida - está longe de se aplicar de forma evidente (Nunes, 2011; Guerriero, Minayo, 2013).

Para assegurar um melhor e mais amplo desenvolvimento da deliberação ética em saúde é importante, em suma, assegurar uma vigilância crítica relativamente à imposição de uma matriz biocêntrica (a aplicação da lógica biomédica sobre a prática da investigação às demais áreas do conhecimento) (Barbosa, Corrales, Silbermann, 2014; Guerriero, Minayo, 2013), assim como uma atenção especial quanto às potenciais restrições e aos efeitos perversos da codificação formal, normativa e universalista dos modelos de deliberação ética, designadamente no campo da pesquisa qualitativa (Dequirez, Hersant, 2013; Nunes, 2011). No âmbito destas abordagens metodológicas mais afastadas da matriz da investigação médica, devem, em contrapartida, ser promovidos exercícios de análise e deliberação ética de índole mais casuística e, no 
fundo, mais alinhadas com o próprio exercício da razão prática. Eis um dos horizontes de melhoria do empreendimento bioético para o qual a Sociologia poderá potencialmente contribuir no decurso da sua intervenção nas estruturas da ética institucionalizada.

\section{Referências}

Barbosa, Adriana Silva; Corrales, Carlos Montero; Silbermann, Marcos (2014), "Controvérsias sobre a revisão ética de pesquisas em ciências humanas e sociais pelo sistema CEP/Conep”, Revista Bioética 22 (3), 482-492.

Cascais, António Fernando (2002), “Genealogia, âmbito e objecto da bioética”, in João Silva, António Barbosa, Fernando Vale (Orgs.), Contributos para a Bioética em Portugal, Lisboa: Cosmos, 47-136.

Cascais, António Fernando (2015), “Comentário: a bioética, ou a crise das regulações. O que é dado à sociologia saber/fazer?”, in Graça Carapinheiro, Tiago Correia (Orgs.), Novos temas de saúde, novas questões sociais, Lisboa: Mundos Sociais, 31-38.

Decreto-Lei n 97/95, de 10 de Maio, Regulamenta as comissões de ética para a saúde.

Dequirez, Gaelle; Hersant, Jeanne (2013), “The virtues of improvisation: Ethnography without an ethics protocol", Current Sociology 65 (5-6), 646-660.

Fins, Joseph; Gracia, Diego (2015), "Entrevista a Daniel Callahan”, Eidon Revista Española de Bioética Nº43, 40-49.

Guerriero, Iara Coelho; Minayo, Maria Cecília (2013), “O desafio de revisar aspectos éticos das pesquisas em ciências sociais e humanas: a necessidade de directrizes específicas”, Physis Revista de Saúde Colectiva, 23 (3), 763-782.

Lopez, José (2004), "How Sociology can save bioethics...maybe", Sociology of Health \& Illness Vol.26 Nº, 875-896.

Marques, Tatiana (2015), “O holofote sociológico sobre a bioética. Constrangimentos e virtualidades", in Graça Carapinheiro, Tiago Correia (Orgs.), Novos temas de saúde, novas questões sociais, Lisboa: Mundos Sociais, 19-29.

Monaghan, Lee; O’Dwyer; Gabe, Jonathan (2013), "Seeking university Research Ethic Committee approval: the emotional vicissitudes of a "rationalised" process", International Journal of Social Research Methodology Vol.16, Nº1, 65-80. 
Neves, Maria do Céu Patrão (1995), “As comissões de Ética Hospitalares e a institucionalização da Bioética em Portugal", Revista Bioética, Vol.3, Nº1.

Nunes, João Arriscado (2011), "Sobre a ética (e a política) da investigação social em saúde", Sociologia On Line No3, 167-188.

Orfali, Kristina; DeVries, Raymond (2010), "A Sociological Gaze on Bioethics", in William Cockerham (Ed.), The New Blackwell Companion to Medical Sociology, London: Wiley- Blackwell, 487-510.

UNESCO (2005), Declaração Universal sobre Bioética e direitos humanos.

Data de submissão: 01/07/2016 | Data de aceitação: 03/08/2016 